\title{
A reaction-diffusion model of cholinergic retinal waves and self-organized criticality
}

\author{
Benjamin J Lansdell, J Nathan Kutz \\ From Twenty Second Annual Computational Neuroscience Meeting: CNS*2013 \\ Paris, France. 13-18 July 2013
}

Prior to receiving visual stimuli, spontaneous, correlated activity called retinal waves drives activity-dependent developmental programs. Early-stage waves mediated by acetylcholine (ACh) manifest as slow, spreading bursts of action potentials. They are believed to be initiated by the spontaneous firing of Starburst Amacrine Cells (SACs), whose dense, recurrent connectivity then propagates this activity laterally. Their extended inter-wave intervals and shifting wave boundaries are the result of the slow after-hyperpolarization of the SACs creating an evolving mosaic of recruitable and refractory cells, which can and cannot participate in waves. Recent evidence suggests that cholinergic waves may be modulated by the extracellular concentration of ACh [1].Here, we have constructed a simplified, yet biophysically realistic, reaction-diffusion model of cholinergic retinal waves capable of recapitulating wave dynamics observed in mice retina recordings (Figure 1A). The dense, recurrent connectivity of SACs is modeled through local, excitatory coupling occurring via the volume release and diffusion of ACh. This novel approach is used to determine how extracellular ACh may modulate wave activity. In contrast with previous, simulation-based models (e.g. the model of Hennig [2]), we are able to use non-linear wave theory (traveling fronts, pulses, singular perturbation analysis, etc.) to connect wave features to underlying physiological parameters, making our model useful in determining appropriate pharmacological manipulations to experimentally produce waves of a prescribed spatiotemporal character (Figure 1B).

This is the first mathematical analysis of its type on retinal waves. However, a number of theoretical issues remain unresolved. The distribution of wave sizes has been reported to obey a power-law distribution, suggesting
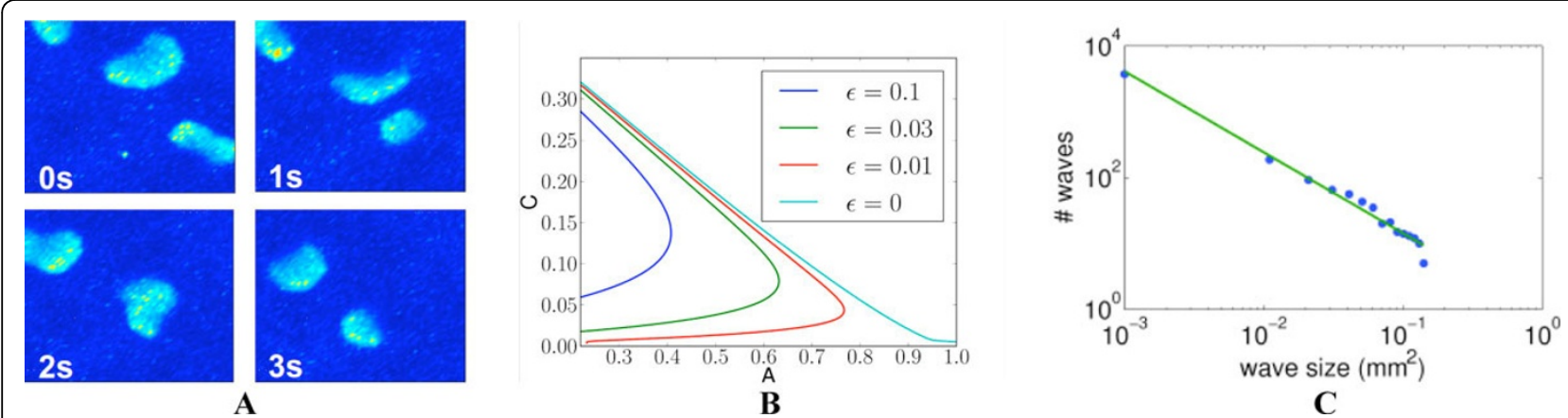

Figure 1 A: Simulated voltage dynamics of model. SACs have Morris-Lecar dynamics, with local coupling occurring via diffusion of extracellular $A C h$, and a noisy channel to induce spontaneous firing. B: Traveling wave speed $C$ as a function of threshold parameter $A$ and refractory timescale $\varepsilon$, computed through numerical continuation. C: Blue points indicate frequency of wave-sizes from 5000s of simulation. Green line indicates fitted power-law distribution with exponent -1.23 , coefficient of determination $r^{2}=0.98$.

\footnotetext{
* Correspondence: lansdell@uw.edu

Department of Applied Mathematics, University of Washington, Seattle, WA 98195, USA
}

\section{() Biomed Central}

(C) 2013 Lansdell and Kutz; licensee BioMed Central Ltd. This is an Open Access article distributed under the terms of the Creative Commons Attribution License (http://creativecommons.org/licenses/by/2.0), which permits unrestricted use, distribution, and reproduction in any medium, provided the original work is properly cited. 
the developing retina may exist in a critical state [2]. Are these findings compatible with our theoretical model? We present preliminary results suggesting that our model possesses a configuration in which wave sizes are distributed according to a power-law (Figure 1C). We adapt analyses typically used in neural field equations to understand the effects of stochasticity and heterogeneity on wave size statistics [3], and therefore provide theoretical arguments characterizing the potential for criticality in retinal development.

\section{Acknowledgements}

The authors would like to thank Kevin Ford for discussions and feedback on this work

Published: 8 July 2013

\section{References}

1. Ford KJ, Felix AL, Feller MB: Cellular mechanisms underlying spatiotemporal features of cholinergic retinal waves. J Neurosci 2012, 32(3):850-863.

2. Hennig MH, Adams C, Willshaw D, Sernagor E: Early-stage waves in the retinal network emerge close to a critical state transition between local and global functional connectivity. J Neurosci 2009, 29(4):1077-1086.

3. Bressloff PC: Spatiotemporal dynamics of continuum neural fields. J Phys A: Math Theor 2012, 45:033001.

doi:10.1186/1471-2202-14-S1-P230

Cite this article as: Lansdell and Kutz: A reaction-diffusion model of cholinergic retinal waves and self-organized criticality. BMC Neuroscience 2013 14(Suppl 1):P230.

\section{Submit your next manuscript to BioMed Central} and take full advantage of:

- Convenient online submission

- Thorough peer review

- No space constraints or color figure charges

- Immediate publication on acceptance

- Inclusion in PubMed, CAS, Scopus and Google Scholar

- Research which is freely available for redistribution

Submit your manuscript at www.biomedcentral.com/submit 